\title{
Experimental Study of Water Transfer and Ice Accumulation in Freezing Soils under Different Conditions
}

\author{
Sihao Liang, ${ }^{1}$ Xinyan $\mathrm{Ma}^{2}{ }^{2}$ Qiang Li, ${ }^{3}$ Xinyu Ye $\mathbb{D}^{1},{ }^{1}$ Jianlong Liu, ${ }^{1}$ and Jian Zhang $\mathbb{D}^{4}$ \\ ${ }^{1}$ School of Civil Engineering, Central South University, Changsha, Hunan 410075, China \\ ${ }^{2}$ China Airport Construction Group Corporation, Beijing 100101, China \\ ${ }^{3}$ Construction Administration of Beijing Daxing International Airport, Beijing 102602, China \\ ${ }^{4}$ Key Laboratory of Ministry of Education for Geomechanics and Embankment Engineering, Hohai University, Nanjing 210024, \\ China
}

Correspondence should be addressed to Xinyu Ye; yexinyu113@csu.edu.cn

Received 17 February 2020; Revised 17 March 2021; Accepted 18 April 2021; Published 28 April 2021

Academic Editor: Timo Saksala

Copyright (c) 2021 Sihao Liang et al. This is an open access article distributed under the Creative Commons Attribution License, which permits unrestricted use, distribution, and reproduction in any medium, provided the original work is properly cited.

\begin{abstract}
A series of tests for water transfer and ice accumulation were conducted under different soil types and conditions of water supply method, temperature gradient, and initial water content; the influence of the above parameters on the efficiency of water and vapor transfer was investigated and discussed. The main conclusions drawn are as follows. First, due to the difference in permeability for different soil type, water (i.e., liquid water and vapor) transfers differently. The water (or ice) accumulated in the soils of calcareous sand, silty soil in Lanzhou (SSL), red clay in Changsha, and silty soil in Hohhot (SSH) under the top plate is $34.5 \%, 21.0 \%, 11.33 \%$, and $26.7 \%$, respectively. In addition, the water (or ice) accumulation is determined by the holding capacity of water. Second, the supply method of liquid water is more efficiently compared with that of vapor supply, with the water contents increasing to $60.5 \%$ and $57.3 \%$ for liquid water and vapor supply. Third, the larger the temperature gradient, the greater the water accumulation in the frozen area. The increased amount of water mass under different temperature boundary conditions is $227.9 \mathrm{~g}, 253.3 \mathrm{~g}$, and $273.8 \mathrm{~g}$, respectively. Finally, the initial water content in silty soil has a significant influence on water and vapor transfer. The increased amounts of water for the tests of the initial water content of 5\%, 10\%, and $15 \%$ are $282.6 \mathrm{~g}, 253.3 \mathrm{~g}$, and $132.5 \mathrm{~g}$, respectively. The smaller the initial water content, the greater the water transfer in the unfrozen zone and vapor transfer in the frozen zone.
\end{abstract}

\section{Introduction}

The foundation of airport runways is fully covered by the cement concrete pavement; the vapor in the deep foundation migrates upward and accumulates in the form of ice crystals under the cement concrete pavement in the winter. However, the massive deposit of ice then melts into water in summer and leads to a reduction in bearing capacity of foundation. Therefore, the study of moisture transfer in foundations, particularly in the condition of large coverage with airtight materials, is important before some effective measures are adopted to prevent the accumulation of ice under the concrete pavement.

In the 1930s, Taber [1] observed the existence of icepermeable crystals through experiments, suggesting that frost heave was produced by the migration of unfrozen water to the frozen front, rather than the volumetric expansion of water freezes. This work firstly proves that the external water supply is the necessary condition resulting in frost heave; in addition, the moisture transfer under the freezing point is the primary source of freezing-leaded problems in the foundations or embankments. Since then, numerous researches have been conducted to study the issues with moisture transfer, for instance, the capillary action theory $[1,2]$, the frozen edge theory $[3,4]$, the hydrothermal coupling theory $[5,6]$, and the theory of segregation potential $[7,8]$. However, those theories mainly focus on the water flow transfer in saturated soils without considering the vapor transfer in the unsaturated conditions.

Recently, it was found that the unique moisture accumulation can take place in arid and semiarid regions, where 
the groundwater table is relatively deep, and the soil is initially very dry. Noting that this phenomenon occurs in soils which have experienced freezing, Li et al. [9] proposed a "pot cover" effect to explain this potential reason. It is said that the moisture transfers upward in a form of air (i.e., vapor transfer) and then accumulates in a form of ice crystal under the ice-cold cover (e.g., cement concrete pavement) in winter and then a large amount of ice crystals melts in summer, leading to the reduction in bearing capacity. Based on this explanation, Teng et al. [10] suggested that the vapor transfer derived from the temperature gradient was the main approach leading to the water accumulation under the pavement, while the possibility of capillary action was eliminated because a deep groundwater table cannot be the source of water supply. Furthermore, Teng et al. [10] discussed that two possible reasons lead to the "pot cover" effect: the first is the vapor condensation in the unsaturated soils; the other is the vapor transfer under freezing condition. Based on the two above two explanations, two analytical models were proposed for the calculation of the accumulation of ice crystals under a "pot cover," which proved that the vapor transfer is the main reason resulting in the "pot cover" effect. Zhang et al. [11] developed an innovative test equipment and then performed a series of vapor transfer tests for clay under the different initial water content and temperature conditions to investigate the occurring and developing mechanism of the "pot cover" effect. In particular, the "pot cover" effect is more significant in the freezing condition after comparing the test results of unfrozen soil. Furthermore, the experimental observations indicated that the water content at the top of frozen samples significantly increased compared with the unfrozen samples, which agrees with the conclusions by Teng et al. [12]. Besides, Gao et al. [13] and Bai et al. [14] conducted a series of frost heave tests of different fine particles and stated that the vapor transfer is essential to the frost heave of coarse-grained soils, especially in the condition of low water content. Therefore, the vapor transfer should be paid much attention in practice to prevent the damage derived from frost heave. Finally, other experimental tests also observed that the silty soil is one of the soil types that is much easier to frost heave compared with other soils such as sand and clay [15-17].

Although the research on formation and development mechanism of the vapor transfer, the subsequent water accumulation, and the further frost heave are conducted, the influence of the boundary, soil type, and environment conditions on the water transfer and ice accumulation needs to be systematically studied, which is quite important to avoid frost heave damage in practice. Particularly, in the design of airport foundation and driveway pavement, the height of frost proof layer, the selection of subsoil when different soil types are available, the initial water content of soil compaction after the maintenance of compactness, and so on can be properly determined based on this study.

In this paper, the tests of water (i.e., liquid water and vapor) transfer were performed for different soil types, including calcareous sand, silty soil in Lanzhou (SSL), red clay in Changsha, and silty soil in Hohhot (SSH). In addition, the influence of water supply method, temperature gradient, and initial water content on the water or ice accumulation under the pavement was comprehensively studied, and its sensibilities were discussed.

\section{Materials and Equipment}

2.1. Materials. The silty soil obtained from Hohhot Airport, China, was used in the laboratory tests. To make a comparison of the water transfer behavior for different soil types, the tests were also conducted for them. The grain size distributions of the soils are shown in Figure 1. The specific gravity of the silty soil ( $\mathrm{SSH}$ ) is 2.67 , and the maximum and minimum densities are $1.74 \mathrm{Mg} / \mathrm{m}^{3}$ and $1.41 \mathrm{Mg} / \mathrm{m}^{3}$, respectively. Moreover, the liquid and plastic limits of the soil are $23.7 \%$ and $13.5 \%$, respectively. Besides, the other typical soil types, including calcareous sand, SSL soil, red clay in Changsha, are adopted to make a comparison of the efficiency of the vapor transfer. Their properties are available in the literature $[12,18,19]$.

2.2. Equipment. A water transfer testing instrument was developed, which is available for monitoring temperatures in a soil sample and controlling the temperature gradient. The instrument contains three major parts: a test model system, a temperature cycle control system, and a data logging system. The schematic diagram of the instrument is presented in Figure 2.

The test model system mainly consists of a plexiglass cylinder, a water supply device, a thermal insulation device, and some mechanical connection devices. The sample cylinder has an outer diameter of $12 \mathrm{~cm}$, an inner diameter of $10 \mathrm{~cm}$, and a height of $20 \mathrm{~cm}$. The plexiglass material of the sample cylinder is strong enough for soil compaction and frost resistance. In addition, the sample height and the changes in soil sample during the tests are easily observed through the transparent cylinder wall. Below the sample cylinder, there is a water supplement device, which is connected to a Mario bottle to control the water table and keep the water height throughout the test process; thus, the efficiency of vapor transfer at constant water table can be studied via this design. It should be noted that the tests with water supply and vapor supply can be achieved by changing the water table in the space between the base pedestal and the soil sample (see Figure 2). As the water table increases to a height that higher than the bottom of soil sample, the water supply method is obtained. Differently, the vapor supply is achieved by leaving a gap between the water and the bottom of the soil sample. The thermal insulation device consists of two metal leaves containing $2 \mathrm{~cm}$ thermal insulation cotton to ensure a one-dimensional temperature gradient. The temperature control system consists of two cryogenic circulation boxes providing constant temperature refrigerant. The temperature control range is between -30 and $+90^{\circ} \mathrm{C}$, and the control accuracy is $0.1^{\circ} \mathrm{C}$. The circulation box is connected to the data logging system. 


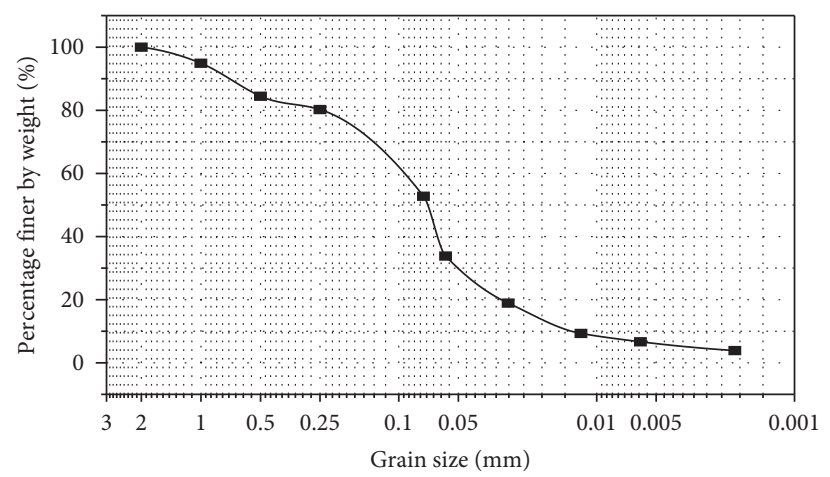

(a)

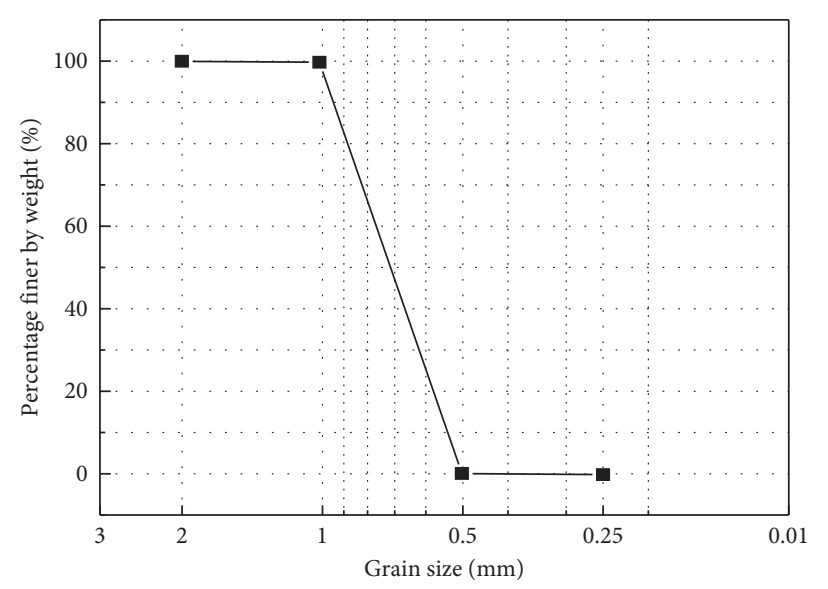

(c)

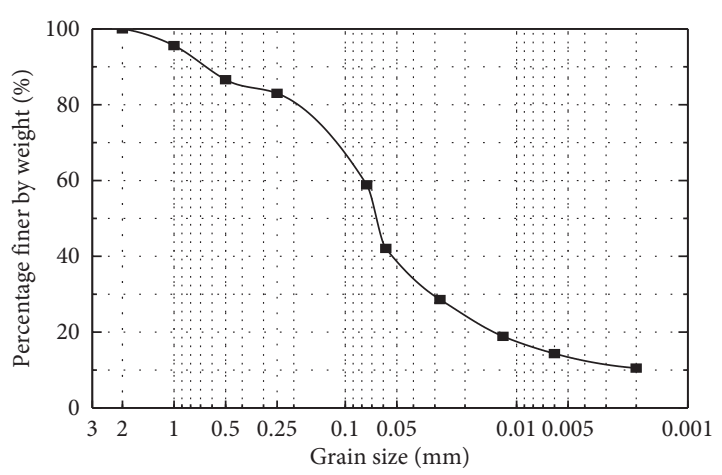

(b)

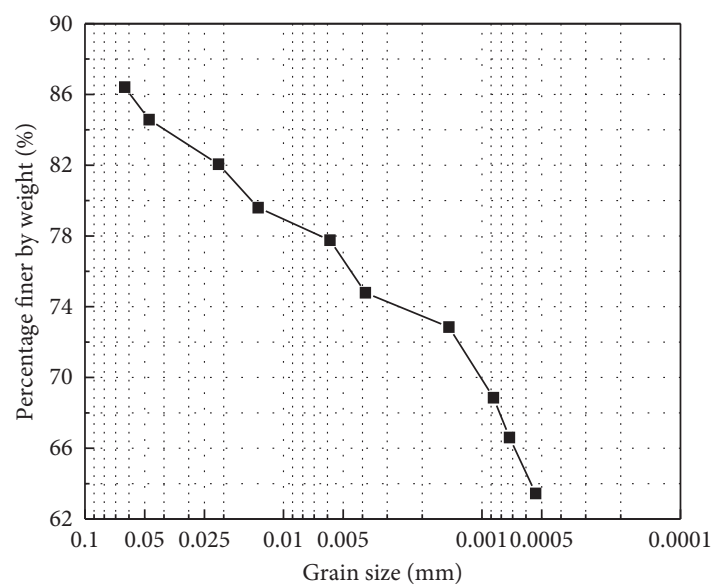

(d)

Figure 1: Grain size distribution of the different soil types. (a) SSH. (b) SSL. (c) Calcareous sand. (d) Red clay.

2.3. Test Program. A series of one-dimensional water transfer tests regarding different soil types, water supply method, temperature gradient, and initial water content were performed using the proposed instrument. The influences of the above conditions on water transfer and the redistribution of the water content in soil samples were then obtained and discussed. The size of the soil sample of $10 \mathrm{~cm}$ in diameter and $13.5 \mathrm{~cm}$ in height was adopted.

Firstly, there is a wide range of soil types in the cold regions around the world; among them, sand, silt, and clay are the three typical ones. In addition, the silty soil is the most commonly used soil for the filling of embankment of airport in Northern China, where it always suffered from the "pot cover" effect; thus, the study of different silty soil in different regions on vapor transfer is also needed. Therefore, the influence of soil types, including calcareous sand, SSL, SSH, and red clay in Changsha, on the vapor transfer was studied in this paper. The initial water content of samples was $5 \%$ and the dry density was $1.5 \mathrm{~g} / \mathrm{cm}^{3}$. The water table was controlled at a relatively low level to achieve the vapor supply (i.e., avoid the water contacting with the soil sample). The top plate (negative temperature) temperature is $-10^{\circ} \mathrm{C}$ and the bottom plate (positive temperature) temperature is $10^{\circ} \mathrm{C}$. Every test lasted for five days, and the test scheme is shown in Table 1.

Secondly, the water table varies seasonally in field, so the water supply method for water transfer is different. It is the liquid water supply method when the water table is high and vice versa.
Therefore, to study the influence of water supply method on the water transfer in soil sample, the tests of different ground water table were conducted. In these tests, the change in water table in Mario bottle results in different water supply method. As the water table was below the bottom of the soil sample, the vapor supply was achieved. The soil sample parameters and temperature controls in the test scheme are shown in Table 2.

Thirdly, it is known that the temperature of land surface varies seasonally across the world, while the temperature in the relative deep foundation keeps constant in the whole year. Hence, different temperature gradient appears, so the study on the influence of different temperature gradient on the water transfer is necessary. In this study, the temperature of the top plate of negative temperature was controlled at $-5^{\circ} \mathrm{C},-10^{\circ} \mathrm{C}$, and $-15^{\circ} \mathrm{C}$, respectively, and the bottom plate of positive temperature was consistently controlled at $10^{\circ} \mathrm{C}$ to study the influence of temperature gradients on water transfer. The test scheme is shown in Table 3.

Lastly, the suction of different degree of saturation (i.e., water content) can be the power to transport the water in soil sample, which then promotes the water transfer. In addition, whether the initial water in soil sample contributes to the water transfer is another interesting issue worth studying. Therefore, the influence of the initial water content on the water transfer was investigated in this study, with the initial water content values of $5 \%, 10 \%$, and $15 \%$, respectively. The test scheme is shown in Table 4. 


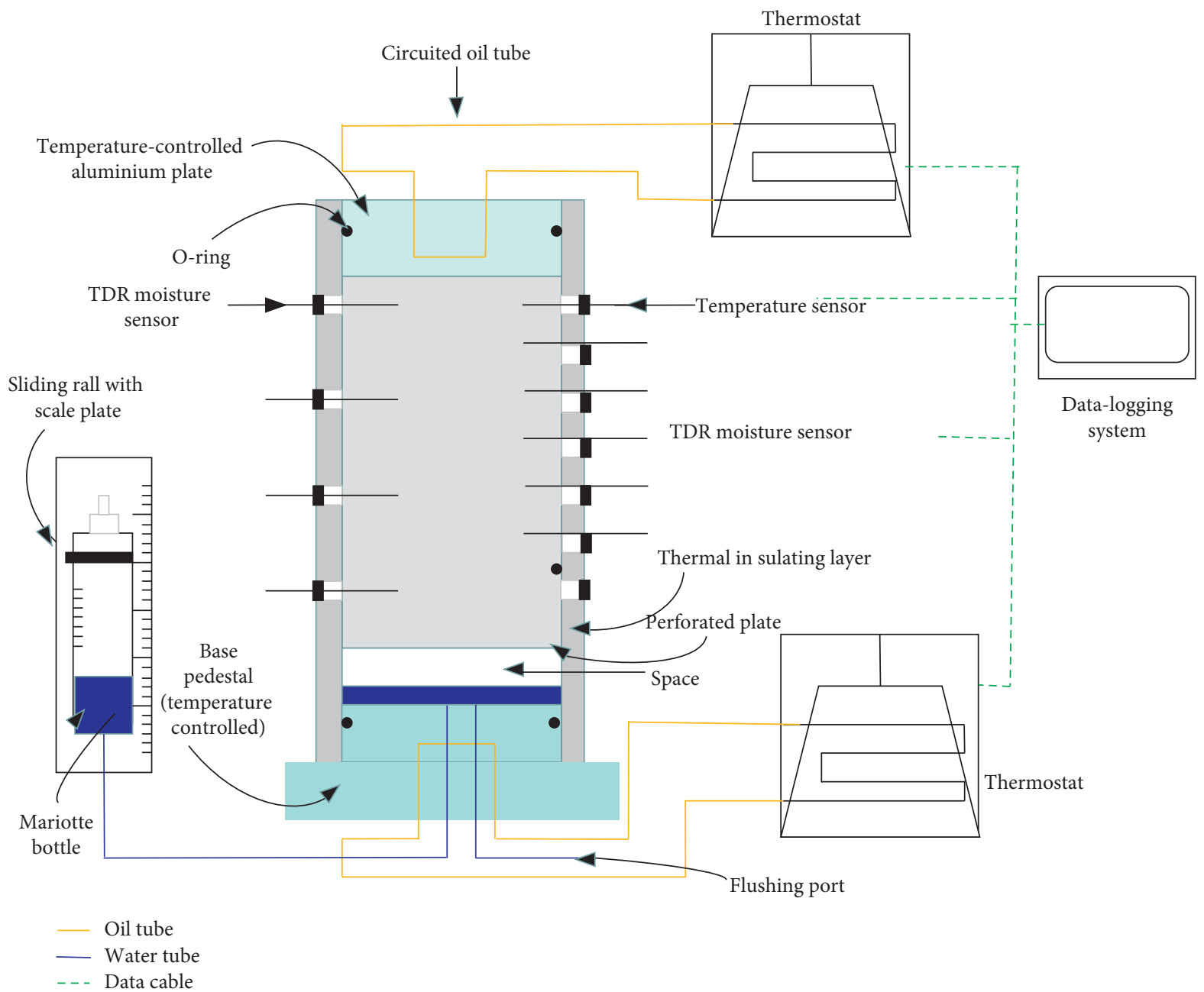

FIgURE 2: Schematic diagram of the vapor transfer test instrument [12].

TABLE 1: Influence of different soil types.

\begin{tabular}{|c|c|c|c|c|c|c|}
\hline $\begin{array}{l}\text { Case } \\
\text { no. }\end{array}$ & Soil types & $\begin{array}{l}\text { Water supply } \\
\text { method }\end{array}$ & $\begin{array}{l}\text { Dry density } \\
\left(\mathrm{g} / \mathrm{cm}^{3}\right)\end{array}$ & $\begin{array}{c}\text { Initial water content } \\
(\%)\end{array}$ & $\begin{array}{l}\text { Duration of test } \\
\text { (d) }\end{array}$ & $\begin{array}{l}\text { Top/bottom } \\
\text { temperature }\end{array}$ \\
\hline 1 & Calcareous sand & & & & & \\
\hline 2 & $\begin{array}{l}\text { Silty soil in Lanzhou } \\
\text { (SSL soil) }\end{array}$ & & & & & \\
\hline 3 & $\begin{array}{l}\text { Red clay in } \\
\text { Changsha }\end{array}$ & Vapor & 1.5 & $5 \%$ & 5 & $-10^{\circ} \mathrm{C} / 10^{\circ} \mathrm{C}$ \\
\hline 4 & $\begin{array}{l}\text { Silty soil in Hohhot } \\
\text { (SSH soil) }\end{array}$ & & & & & \\
\hline
\end{tabular}

TABLE 2: Influence of water supply method for SSH.

\begin{tabular}{lccccc}
\hline Case no. & Supply method & Dry density $\left(\mathrm{g} / \mathrm{cm}^{3}\right)$ & Initial water content $(\%)$ & Duration of test $(\mathrm{d})$ & Top/chassis temperature \\
\hline 5 & Liquid water & 1.5 & $10 \%$ & 5 & $-10^{\circ} \mathrm{C} / 10^{\circ} \mathrm{C}$ \\
6 & Vapor & 1.5 & & 5 \\
\hline
\end{tabular}

\section{Result and Discussion}

3.1. The Influence of Soil Type. Figure 3 shows the initial mass and increased mass of water in different soils before and after the water transfer tests. For calcareous sand, SSL soil, and $\mathrm{SSH}$ soil, the increased masses of water are $24.0 \mathrm{~g}, 29.5 \mathrm{~g}$, and
$32.5 \mathrm{~g}$, respectively. However, due to the low permeability, the increased value of the red clay tends to be zero. The accumulated water (or ice) under the top plate is mainly from the soil in the zone of positive temperature, and the power for the vapor transfer is the temperature gradient and the matric potential in soils. In general, the silty soil, 
TABLE 3: Influence of temperature gradient in SSH.

\begin{tabular}{|c|c|c|c|c|c|}
\hline Case no. & Supply method & Dry density $\left(\mathrm{g} / \mathrm{cm}^{3}\right)$ & Initial volumetric water content (\%) & Duration of test $(\mathrm{d})$ & Top/chassis temperature \\
\hline 7 & & & & & $-5^{\circ} \mathrm{C} / 10^{\circ} \mathrm{C}$ \\
\hline 5 & Liquid water & 1.5 & $10 \%$ & 5 & $-10^{\circ} \mathrm{C} / 10^{\circ} \mathrm{C}$ \\
\hline 8 & & & & & $-15^{\circ} \mathrm{C} / 10^{\circ} \mathrm{C}$ \\
\hline
\end{tabular}

TABLE 4: Influence of initial water content in SSH.

\begin{tabular}{|c|c|c|c|c|c|}
\hline Case no. & Supply method & Dry density $\left(\mathrm{g} / \mathrm{cm}^{3}\right)$ & Initial water content (\%) & Duration of test $(\mathrm{d})$ & Top/chassis temperature \\
\hline 9 & & & $5 \%$ & & \\
\hline 5 & Liquid water & 1.5 & $10 \%$ & 5 & $-10^{\circ} \mathrm{C} / 10^{\circ} \mathrm{C}$ \\
\hline 10 & & & $15 \%$ & & \\
\hline
\end{tabular}

including the SSH and SSL in this study, experienced the largest water increase. Therefore, the soil type significantly influences the vapor transfer.

Figure 4 shows the distribution of the water content with depth of different soil types after the vapor transfer test. As the soil type has a significant influence on the vapor transfer, the water (or ice) accumulated in the soils of calcareous sand, SSL, red clay, and SSH under the top plate, with the water content being $34.5 \%, 21.0 \%, 11.33 \%$, and $26.7 \%$, respectively. It is known that clay and sand have the lowest and highest permeability among the tested soils. In addition, since the tests were conducted under the supply method of vapor, the permeability plays the dominant role in vapor transfer. The result proves this conclusion that more water is accumulated at the top of the soil sample for the soil of higher permeability. Although the total increase in water masses for different soil types was observed, the water content distributions in different soil columns need further discussion.

As shown in Figure 4, the frozen front positions (the peak point) of calcareous sand, SSL, red clay, and SSH are at $10.6 \mathrm{~cm}, 11.5 \mathrm{~cm}, 11.5 \mathrm{~cm}, 11.5 \mathrm{~cm}$ height, respectively. The water content at the frozen front position in the calcareous sand sample reached $23.2 \%$, while the corresponding water content values for the SSL and SSH are $8.1 \%$ and $9.0 \%$, respectively. Noting that there is no peak point for the red clay, the reason for this is that the red clay has quite low permeability, leading to a very small amount of water replenishment. The water under the top plate mainly comes from the initial water in the soil, and the slight decrease in water content in the lower height of soil proves this. In addition, the mean pore diameter of silt is small, and the vapor is prone to condensation after entering the soil; as a result, the water content in the positive temperature zone then increased. Subsequently, comparing with the red clay soil, there will be more vapor transfer and water accumulation for the silty soils under the top plate. For the calcareous sand at such low water content, the liquid water in the soil will not flow downward under the action of gravity. In addition, the adsorption force on the surface of ice crystals promotes the migration of unfrozen water to the frozen zone, leading to the reduction in water content in the positive temperature zone. However, as a whole, the water in the calcareous sand sample increased much (see Figure 3) due to vapor transfer from the environment (i.e., Mariotte bottle), which is different from the red clay sample that the

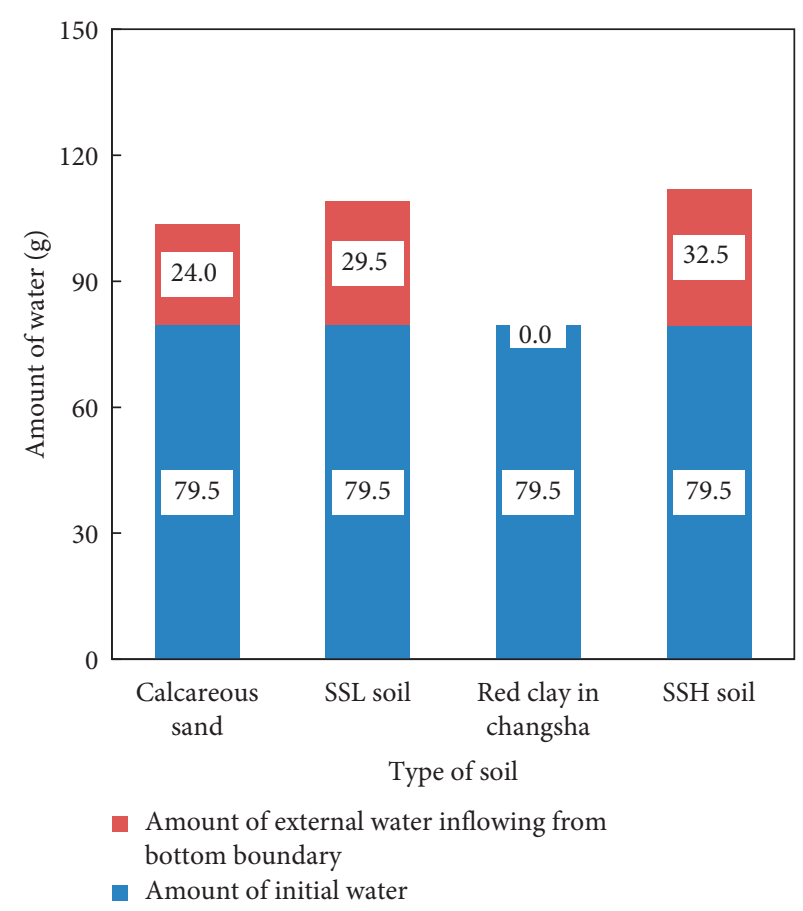

Figure 3: Amount of water in samples of different soil type.

no vapor transfer occurs between the outside water supplement and the soil sample.

3.2. The Influence of Water Supply Method. To study the influence of water supply method on vapor transfer, two tests were carried out for the soil sample of SSH. A steady temperature distribution in samples during the test processes is shown in Figure 5. The temperature in the soil sample is approximately linearly distributed, and the frozen fronts of vapor supply and liquid water supply are at $12.0 \mathrm{~cm}$ and $11.5 \mathrm{~cm}$ height. The temperature at the top of the sample is measured by a sensor placed right the bottom of the negative temperature plate (top plate). Once the sensor contacts the sample, a sudden change of temperature was observed due to the difference in thermal conductivity between the soil and the top plate.

As a whole, the increased amount of water mass in the soil sample of different water supply method is shown in 


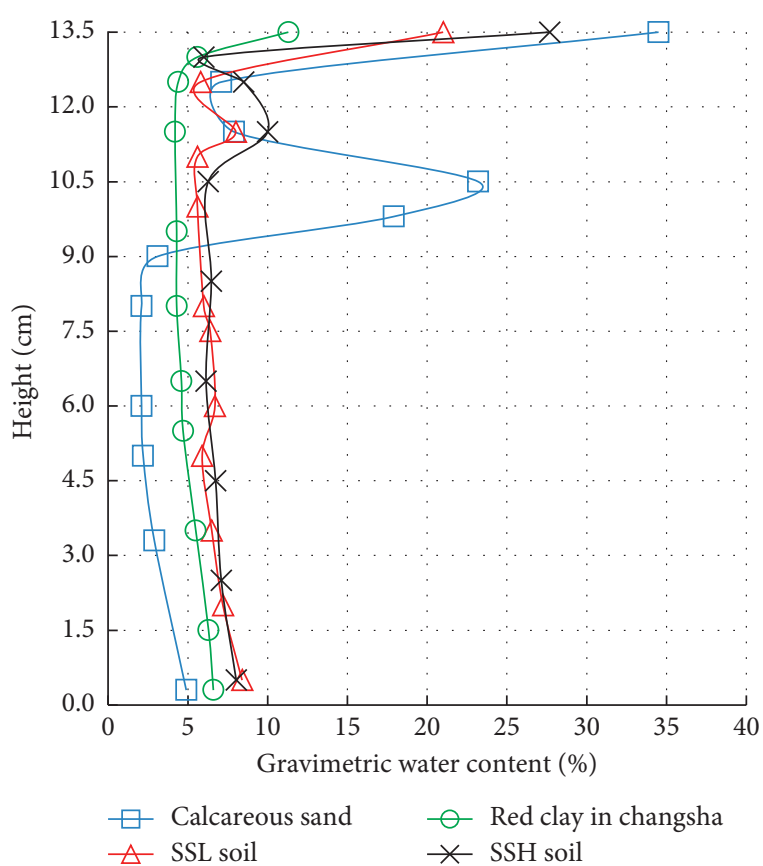

Figure 4: Water content distribution of different soil type.

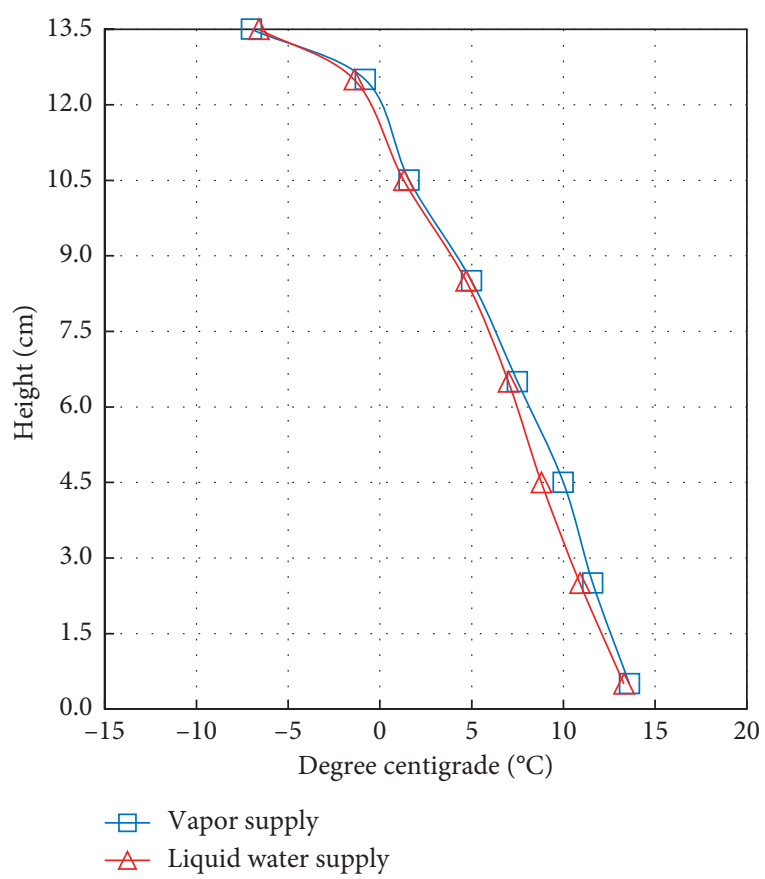

FIGURE 5: Measured temperature distribution of different water supply method.

Figure 6. The increased water mass in five days is $106.1 \mathrm{~g}$ for the vapor supply method, which accounts for $66.7 \%$ of the initial water mass. Under the condition of liquid water supply, the increased water mass is $253.3 \mathrm{~g}$, accounting for $159.3 \%$ of the initial value. Although the water transfer is more remarkable for the liquid water supply method, it cannot be neglected under the vapor supply condition since the increased water mass by vapor transfer is still in a large amount compared with the initial water content. In particular, the vapor transfer will be enlarged when a larger temperature gradient appears in practice.

Figure 7 shows the final distribution of water content in soil samples. The curves for the liquid water supply and vapor supply are in similar shape but different absolute values. The phenomenon of water accumulation can be observed, and the water contents are $60.5 \%$ and $57.3 \%$ for liquid water and vapor supply. At the frozen front position, the water contents are much smaller, with $29.5 \%$ and $22.4 \%$ being shown, respectively. The overall water content for the test of liquid water supply is larger than the other; the possible reason can be drawn as follows: the water transfer with liquid water supply is mainly driven by the matric potential, while the water transfer with vapor supply is determined by the temperature gradient, from which the condensation and deposition of liquid and vapor water then happen [20]. The water transfer driven by matric potential plays the dominant role, so more significant water transfer occurred in the soil samples with liquid water supply comparing with that of vapor supply.

3.3. The Influence of Temperature Gradient. Vapor transfer tests were performed for samples of different temperature gradients, and the stabilized temperature distributions along the soil columns are shown in Figure 8. The trends of those temperature distributions are the same, and they are approximately linear. Under the boundary temperature conditions of $-5^{\circ} \mathrm{C} / 10^{\circ} \mathrm{C},-10^{\circ} \mathrm{C} / 10^{\circ} \mathrm{C}$ and $-15^{\circ} \mathrm{C} / 10^{\circ} \mathrm{C}$, the zerodegree line (freezing front) is at $12.5 \mathrm{~cm}, 11.5 \mathrm{~cm}$ and $10.5 \mathrm{~cm}$ height, respectively. With a lager temperature gradient, a lower position of the freezing front was exhibited.

Figure 9 shows the increased amount of water mass under different temperature boundary conditions of $-5^{\circ} \mathrm{C}$ / $10^{\circ} \mathrm{C},-10^{\circ} \mathrm{C} / 10^{\circ} \mathrm{C}$, and $-15^{\circ} \mathrm{C} / 10^{\circ} \mathrm{C}$, with the increased water masses being $227.9 \mathrm{~g}, 253.3 \mathrm{~g}$, and $273.8 \mathrm{~g}$, respectively. It is clearly seen that the transferred water increases with the increase in the temperature gradient under the same conditions. In this case, a higher depth of freezing zone formed, and a more significant pumping effect subsequently occurs, so more ice is accumulated under the top plate. That means the lower temperature of environment results in a larger amount of water (or ice) accumulation under the pavement or airport driveway.

Figure 10 shows the water content distribution in soil columns under different temperature gradients. It can be observed that the trends of the water content distribution for the tests are similar, and there is a large amount of water (i.e., ice) accumulation under the top plate. The water contents in the top of soil sample reached $59.0 \%, 60.5 \%$, and $68.2 \%$ for the tests at the boundaries of $-5^{\circ} \mathrm{C} / 10^{\circ} \mathrm{C},-10^{\circ} \mathrm{C} / 10^{\circ} \mathrm{C}$, and $-15^{\circ} \mathrm{C} / 10^{\circ} \mathrm{C}$. Accordingly, the water accumulation at the freezing front height was also obvious, with the water content increasing to $31.2 \%, 29.5 \%$, and $29.1 \%$, respectively. As a whole, the water content at the top of the sample and the frozen front is approximately the same under different temperature gradient conditions. In the frozen area, the final water content in the soil sample increases with the increase 


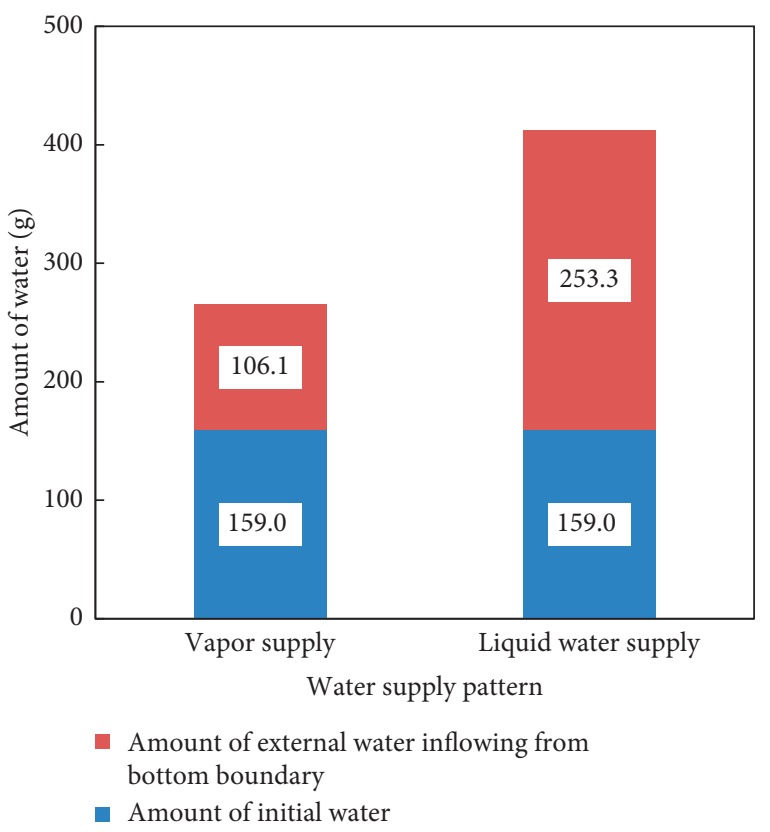

Figure 6: Amount of water in samples of different water supply method.

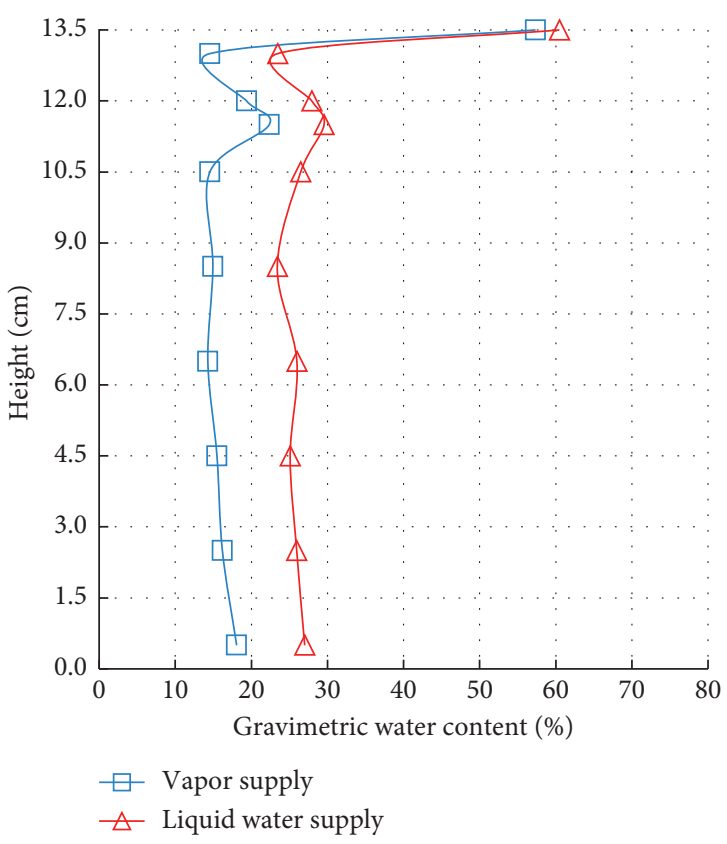

FIGURE 7: Water content distribution of different water supply method.

of the temperature gradient. The water freezes into ice and the frozen water acts as a pump to provide power for vapor transfer, and then an ice layer appears. The test of larger temperature gradient has the thicker ice layer, so the frozen height reaches the lower position, and the accumulated water or ice is more. In the unfrozen area, there is no significant difference in the final water content, which means temperature gradient has little influence on the water transfer in the tests of liquid water supply. The water transfer in silty soil is mainly powered by capillary action; thus, the influence of temperature gradient on the water content can be neglected. Based on this reason, the increase of water in the area of positive temperature is closely related to the water holding capacity of the soil; that is, the soil water characteristic curve is the key to the water increase in unfrozen zone.

3.4. Influence of Initial Water Content. Tests were performed on soil samples of different initial water contents. The stabilized temperature distributions in the soil column are shown in Figure 11. The initial water content has little influence on the temperature distribution in the soil sample, with a similar linear trend shown. The zero-temperature line (freezing front) is between $11.5 \mathrm{~cm}$ and $12 \mathrm{~cm}$.

The increased water mass under different conditions of initial water content is shown in Figure 12. The increased amounts of water for the tests of the initial water content of $5 \%, 10 \%$, and $15 \%$ are $282.6 \mathrm{~g}, 253.3 \mathrm{~g}$, and $132.5 \mathrm{~g}$, respectively. More water was transferred into the soil sample for the tests of smaller initial water content. As discussed, the smaller initial water content has the higher matrix potential in unfrozen zone and higher freezing pumping effect in frozen zone; hence, the water transfer is more remarkable. In addition, another reason is the difference in permeability of the soil sample under different initial water content. According to the study of [19], the soil sample of lower water content normally has higher permeability, which then results in a larger amount of water transferred. Furthermore, the difference in the total water in the three soil samples after tests is relatively minimal. This is because the water in the unfrozen zone accounts for a large proportion of the soil sample, which will reach a limited level for the three tests.

Figure 13 shows the water distribution in the soil sample under the condition of different initial water contents. In 


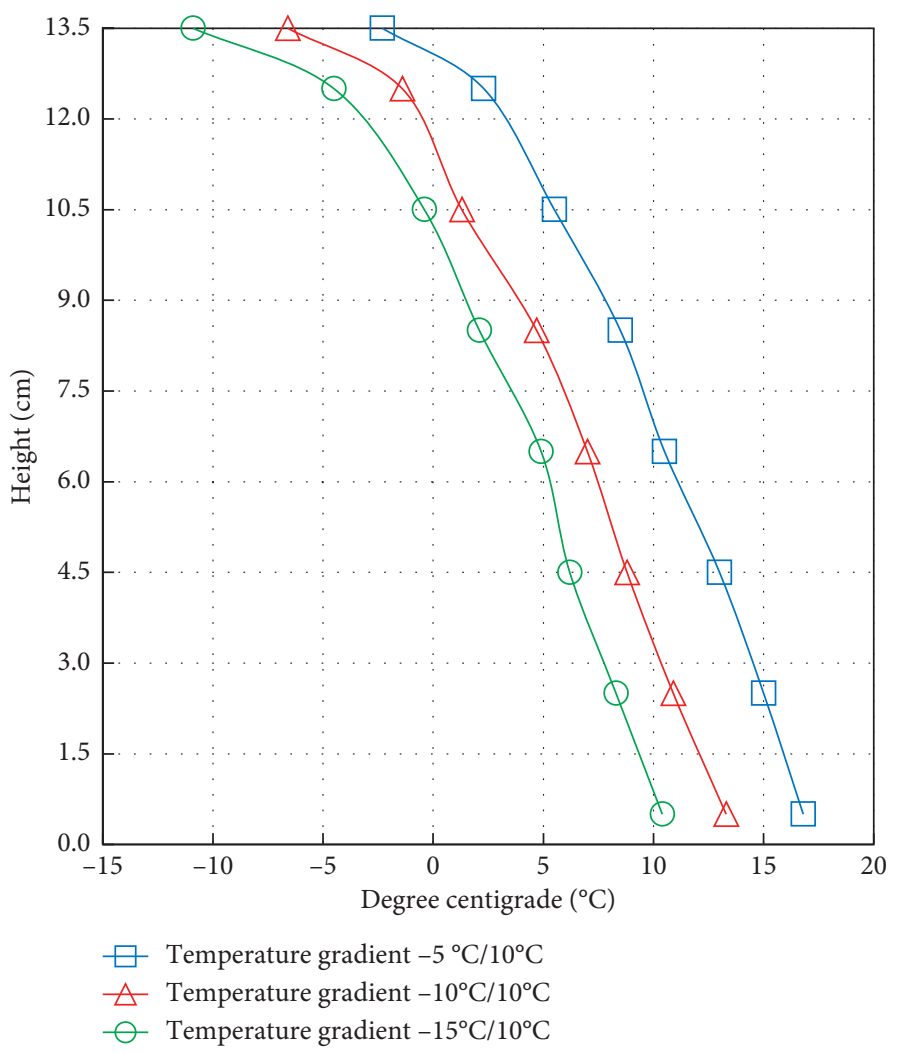

FIGURE 8: Measured temperature distributions of different temperature gradients.

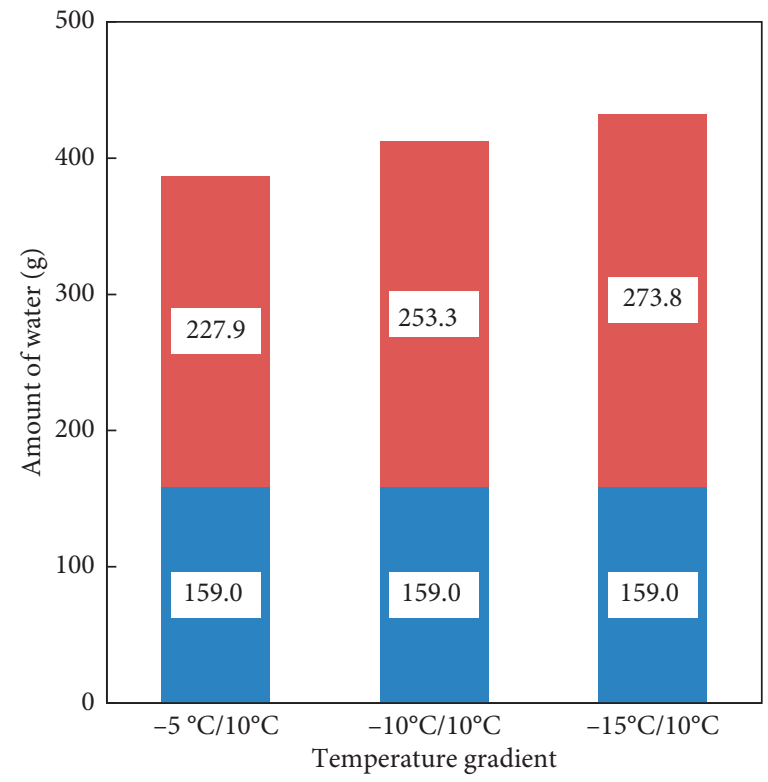

- Amount of external water inflowing from bottom boundary

- Amount of initial water

Figure 9: Amount of water in the samples of different temperature gradients. 


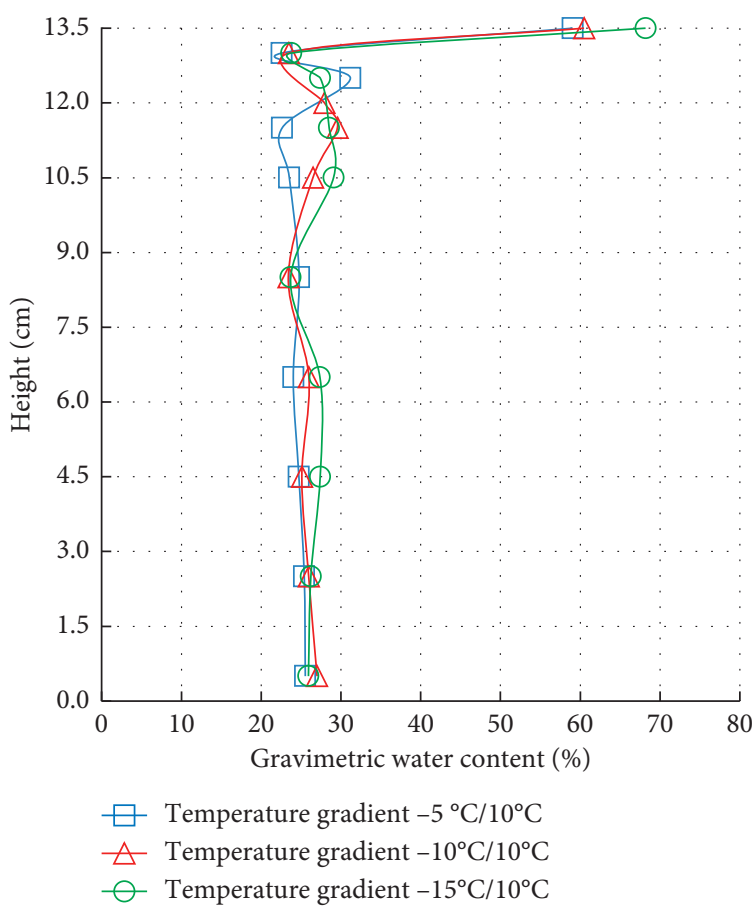

Figure 10: Water content distribution of different temperature gradients.

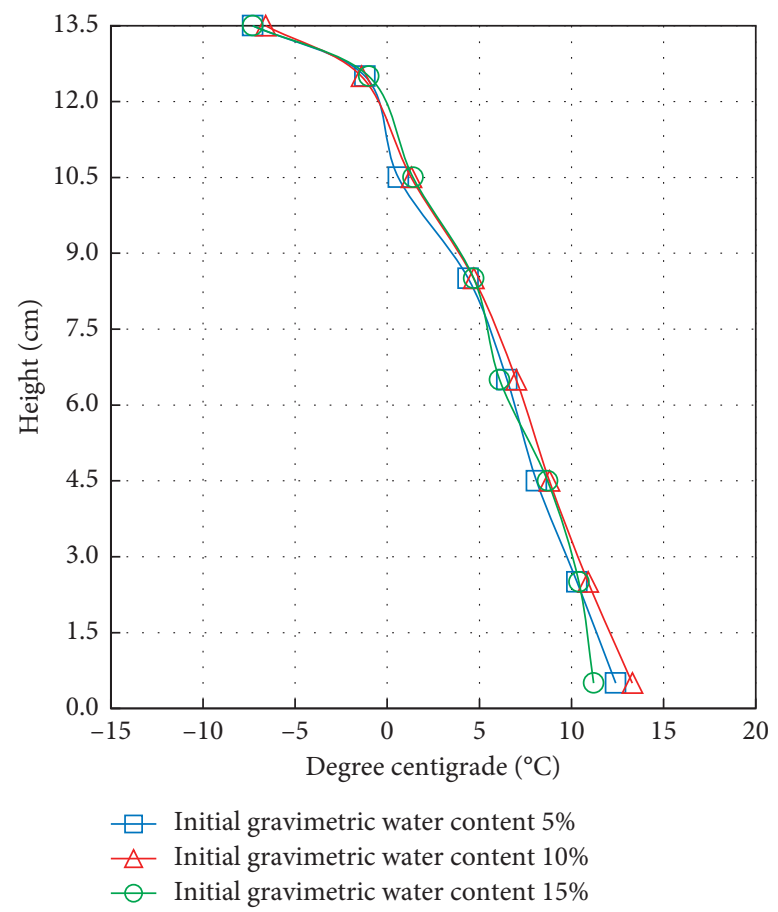

FIGURE 11: Measured temperature distribution of different initial water content.

general, the soil water content similarly varies with the height of soil column for the three tests. In addition, there is a large amount of water (or ice) accumulation under the top plate, with larger water accumulation for the lower initial water content. The possible reason is that the water accumulated under the top plate is mainly derived from water transfer, and the soil of smaller initial water content has a higher matrix potential and permeability, which results in a higher power and efficiency for water transfer. Moreover, the water content experienced a peak at the position of 


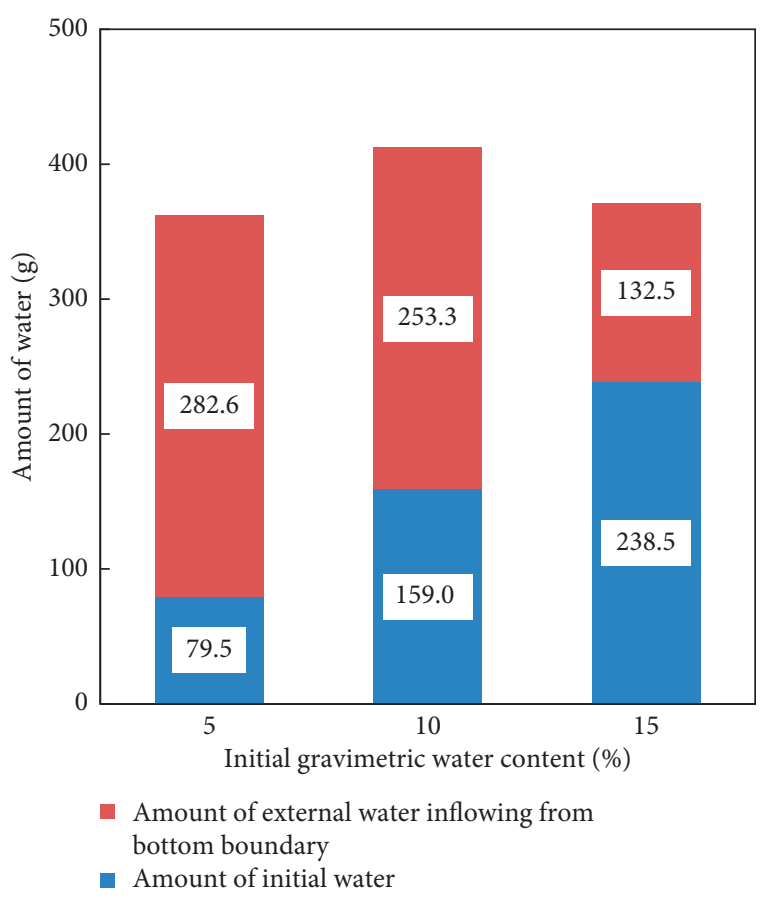

Figure 12: Amount of water in samples of different initial water content.

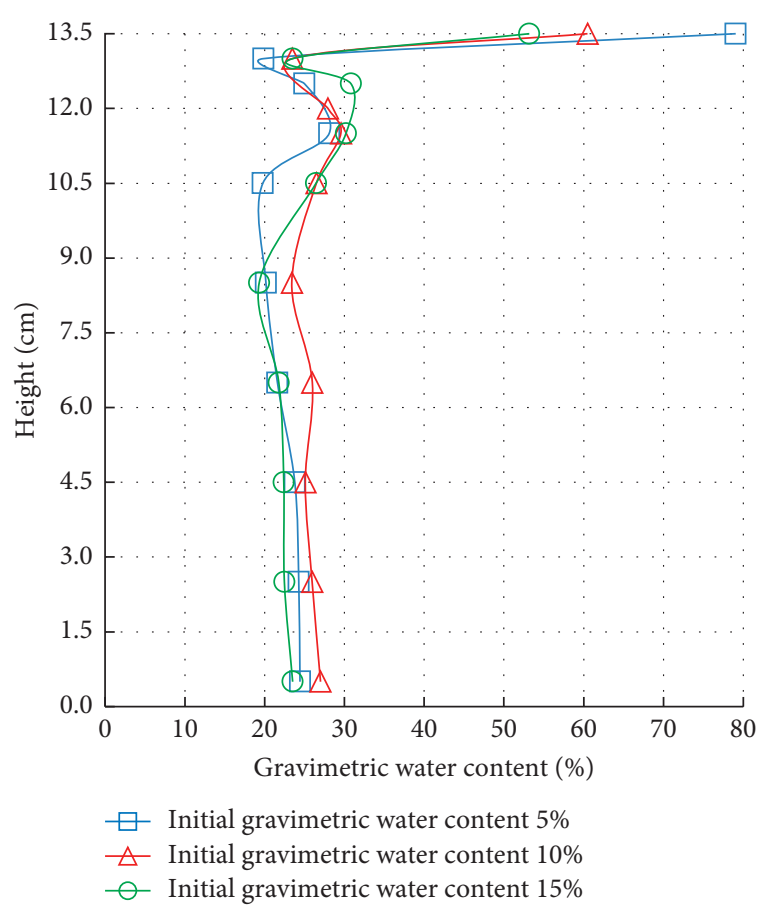

FIGURE 13: Water content distribution of different initial water content.

frozen front for the three tests, and the accumulated amount of water at the frozen front and below this position is almost the same. At the beginning of the test, the sample with lower water content has a larger matrix potential and then a larger amount of water migrated upward. However, the matrix potential of the soil decreases as the water content of the soil increases, and the amount of water supplied decreases during this process. Due to the limited holding capacity for water in the soil, the water content eventually reaches an equilibrium state. Therefore, the final water content at and below the frozen front is basically the same.

\section{Conclusion}

In this study, the tests for water transfer and ice accumulation were conducted under different soil types and conditions of water supply method, temperature gradient, and initial water content; the influence of the above parameters on the efficiency of water transfer was investigated and discussed. The main conclusions are drawn:

(1) Due to the difference in permeability of different soil type, the water (or ice) is accumulated in the soils, including calcareous sand, SSL, red clay, and SSH,differently under the top plate, with the water content being $34.5 \%, 21.0 \%, 11.33 \%$, and $26.7 \%$, respectively. The vapor transfers the most in sand sample and least in clay sample. However, with a relatively higher holding capacity of water for silty soil, the accumulated water (or ice) is more.

(2) The supply method of liquid water in the silty soil can promote water transfer and ice accumulation. The increased water mass in five days is $106.1 \mathrm{~g}$ for the vapor supply method, which accounts for $66.7 \%$ of the initial water mass. Under the condition of liquid water supply, the increased water mass is $253.3 \mathrm{~g}$, accounting for $159.3 \%$ of the initial value. However, the vapor supply method can also provide water source for the water accumulation under the top plate, which cannot be ignored in practice.

(3) Temperature has a significant influence on the water transfer during freezing process in silty soil. The increased amount of water mass under different temperature boundary conditions is $227.9 \mathrm{~g}, 253.3 \mathrm{~g}$, and $273.8 \mathrm{~g}$, respectively. The larger the temperature gradient, the greater the water accumulation is in the frozen area.

(4) The initial water content in silty soil has a significant influence on water transfer. The increased amounts of water for the initial water contents of $5 \%, 10 \%$, and $15 \%$ are $282.6 \mathrm{~g}, 253.3 \mathrm{~g}$, and $132.5 \mathrm{~g}$, respectively. The smaller the initial water content, the greater the water transfer in unfrozen zone and vapor transfer in frozen zone. After a period of time, the final water content of the soil sample in unfrozen zone tends to be consistent at a limited value regardless of the initial water content.

\section{Data Availability}

The data used to support the findings of this study are available from the corresponding author upon request. 


\section{Conflicts of Interest}

The authors declare that they have no conflicts of interest.

\section{References}

[1] S. Taber, "The mechanics of frost heaving," The Journal of Geology, vol. 38, no. 4, pp. 303-317, 1930.

[2] D. H. Everett, "The thermodynamics of frost damage to porous solids," Transactions of the Faraday Society, vol. 57, pp. 1541-1551, 1961.

[3] K. O'neill and R. D. Miller, "Exploration of a rigid ice model of frost heave," Water Resources Research, vol. 21, no. 5, pp. 281-296, 1985.

[4] D. Sheng, "Thermodynamics of freezing soils, theory and application," Doctoral Dissertation, Luleå University of Technology, Luleå, Sweden, 1994.

[5] R. L. Harlan, "Analysis of coupled heat-fluid transport in partially frozen soil," Water Resources Research, vol. 9, no. 5, pp. 1314-1323, 1973.

[6] Y. Lai, W. Pei, M. Zhang, and J. Zhou, "Study on theory model of hydro-thermal-mechanical interaction process in saturated freezing silty soil," International Journal of Heat and Mass Transfer, vol. 78, pp. 805-819, 2014.

[7] J.-M. Konrad and N. R. Morgenstern, "A mechanistic theory of ice lens formation in fine-grained soils," Canadian Geotechnical Journal, vol. 17, no. 4, pp. 473-486, 1980.

[8] J.-M. Konrad, "Estimation of the segregation potential of finegrained soils using the frost heave response of two reference soils," Canadian Geotechnical Journal, vol. 42, no. 1, pp. 38-50, 2005.

[9] Q. Li, Y. Yao, L. Han, J. Hu, R. Peng, and N. Wang, "Pot-cover effect of soil," Industrial Construction, vol. 44, no. 2, pp. 69-71, 2014, (in Chinese).

[10] J. Teng, Z. He, S. Zhang, and D. Sheng, "Moisture transfer and phase change in unsaturated soils: physical mechanism and numerical model for two types of "canopy effect" "Chinese Journal of Geotechnical Engineering, vol. 38, no. 10, pp. 1813-1821, 2016, (in Chinese).

[11] S. Zhang, Z. He, J. Teng, Y. Liu, and D. Heng, "Moisture transfer and phase change in unsaturated soils: physical mechanism and numerical model for two types of "canopy effect"' Chinese Journal of Geotechnical Engineering, vol. 39, no. 5, pp. 961-968, 2017, (in Chinese).

[12] J. Teng, F. Shan, Z. He, S. Zhang, G. Zhao, and D. Sheng, "Experimental study of ice accumulation in unsaturated clean sand," Géotechnique, vol. 69, no. 3, pp. 251-259, 2019 b.

[13] J. Gao, Y. Lai, M. Zhang, and Z. Feng, "Experimental study on the water-heat-vapor behavior in a freezing coarse-grained soil," Applied Thermal Engineering, vol. 128, pp. 956-965, 2018.

[14] R. Bai, Y. Lai, M. Zhang, and J. Gao, "Water-vapor-heat behavior in a freezing unsaturated coarse-grained soil with a closed top," Cold Regions Science and Technology, vol. 155, pp. 120-126, 2018.

[15] J. Simunek, K. Huang, and M. van Genuchten, The Hydrus-Et Software Package For Simulating The One-Dimentional Movement Of Water, Heat And Multiple Solutes In VariablySaturated Media, Version 1.1, Slovak Academy of Sciences, Bratislava, Slovakia, 1997.

[16] D. Sheng, S. Zhang, Z. Yu, and J. Zhang, "Assessing frost susceptibility of soils using PCHeave," Cold Regions Science and Technology, vol. 95, no. 11, pp. 27-38, 2013.
[17] E. Song, R. Tong, S. Luo, and P. Li, "Numerical simulation and analysis of 'time-varying Canopy effect' of moisture transport in subgrade soil," Engineering Mechanics, vol. 36, no. 8, pp. 30-39, 2019, (in Chinese).

[18] Y. He, R. Huang, Y. Chen, and W. Ye, "Water retention properties of deformable compacted red clay induced by wetting and drying," Journal of Central South University (Science and Technology), vol. 47, no. 1, pp. 143-148, 2016.

[19] J. Teng, J. Kou, S. Zhang, and D. Sheng, "Evaluating the influence of specimen preparation on saturated hydraulic conductivity using nuclear magnetic resonance technology," Vadose Zone Journal, vol. 18, 2019.

[20] S. Zhang, J. Teng, Z. He, and D. Sheng, "Importance of vapor flow in unsaturated freezing soil: a numerical study," Cold Regions Science and Technology, vol. 126, pp. 1-9, 2016. 